\title{
Management of irritable bowel syndrome
}

\author{
M C Gunn, A A Cavin, J C Mansfield
}

Postgrad Med J 2003;79:154-158

The diagnosis of irritable bowel syndrome (IBS) is made on clinical grounds with appropriate limited investigations to exclude organic disease. IBS is common and may have a significant impact on a patient's quality of life. Psychological symptoms are common. IBS may benefit from pharmacological and non-pharmacological management. Specific measures should be directed towards the dominant symptoms of constipation or diarrhoea. Several new drugs are currently under evaluation and may prove valuable for subgroups of patients with IBS. Successful management requires a combination of reassurance and explanation about the natural history of the condition.

See end of article for authors' affiliations

Correspondence to: Dr John Mansfield, Royal Victoria Infirmary, Newcastle upon Tyne NE 1 4LP; UK;

John.mansfield@

nuth.northy.nhs.uk

Submitted 2 August 2002

Accepted

16 October 2002 rritable bowel syndrome (IBS) is a chronic functional bowel disorder, accounting for 36\%$50 \%$ of gastrointestinal consultations, although the majority of patients suffering from the condition do not seek medical advice. IBS has a considerable impact on health care resources both at the level of the primary care physician and in the hospital setting, yet management of IBS is predominantly based on clinical expertise.

There have been several recent reviews of the epidemiology, pathophysiology, and management of the condition ${ }^{1-4}$ and the British Society of Gastroenterology published Guidelines for the management of the irritable bowel syndrome in November $2000 .^{5}$ Overall, there is little evidence on which to base our current clinical practice, predominantly due to poorly conducted trials, lack of definitive end points such as mortality, and poorly defined disease entities. This article aims to summarise and update the management of IBS; other functional gastrointestinal disorders will not be addressed in this review.

\section{DEFINITION}

IBS is defined as "a functional bowel disorder in which abdominal pain is associated with defecation or a change in bowel habit, with features of disordered defecation and distension". ${ }^{6}$ The Manning criteria ${ }^{7}$ are used predominantly for research definition with a modified Rome criteria (Rome II) ${ }^{6}$ forming the consensus definition of IBS. However, it is recognised that the modified criteria of Rome II have limited application in the clinical setting, which if solely relied upon would exclude IBS variants well recognised by experienced clinicians. Therefore, the definition is based on a series of criteria and clinical evaluation of the patient with appropriate limited investigations to exclude organic disease. ${ }^{4}$

\section{EPIDEMIOLOGY}

The prevalence of IBS is up to $20 \%$; $14 \%-24 \%$ of women and 5\%-19\% men. ${ }^{90}$ The female to male ratio varies from 1.1-2.6 depending on the predominant symptom; constipation is commoner in women whereas men have a tendency to diarrhoea. ${ }^{9}$ The incidence of IBS declines with age, ${ }^{10}{ }^{11}$ although a recent large UK study suggests that the influence of age is small. ${ }^{12}$ IBS is a disorder recognised worldwide, although prevalence varies. $^{13}$

\section{SOCIAL AND ECONOMIC IMPACT OF IBS}

IBS is the most common diagnosis in gastroenterology clinics reaching up to $50 \%$ of consultations. Patients have a significant economic impact on health care with increased consultations for minor ailments, over-representation in gynaecological and surgical outpatients, inappropriate surgical procedures, ${ }^{14}$ and absenteeism from work. ${ }^{15}{ }^{16}$ Over $40 \%$ of patients with IBS exhibit avoidance of normal social activities ranging from exclusion of food types to avoidance of work and leisure related activities. ${ }^{17}$ Patients report a poorer quality of life, which in turn may have an impact on the perceived severity of their condition. ${ }^{18}$

\section{AETIOLOGY}

\section{Psychological factors}

Significant psychological symptoms prevail in IBS particularly in those who are referred to gastroenterology clinics. Up to $50 \%$ of patients suffer from paranoia, anxiety, depression, somatisation, and phobias at presentation and patients have higher scores of anxiety, depression, and sleep disturbances in comparison with controls (as referenced in Camilleri ${ }^{4}$ and Jones et al ${ }^{5}$ ). In comparison with the general population there is a two to threefold increase in a history of physical/sexual abuse. ${ }^{190}$ Despite this, however, the presence of psychological symptoms is not a reliable distinguisher between organic and functional disease.

IBS patients also exhibit abnormal illness behaviour with increased consultation for minor ailments, multiple somatic complaints, ${ }^{21}$ and are more likely to believe that an organic condition underlies their symptoms rather than a stress related problem. ${ }^{22}$

\section{Physiological factors}

Altered somatovisceral sensitivity and motor dysfunction of the intestine are thought to be possible pathophysiological mechanisms involved in

Abbreviations: $5-\mathrm{HT}_{3}$, serotonin-3; $5-\mathrm{HT}_{4}$, serotonin-4; IBS, irritable bowel syndrome; SSRI, specific serotonin reuptake inhibitors 


\section{Box 1: Criteria for diagnosis of IBS}

- Manning criteria

1. Abdominal pain.

2. Loose stools with onset of pain

3. More frequent stools with onset of pain

4. Abdominal distension.

5. Passage of mucus in stools.

6. Sensation of incomplete evacuation.

- Revised Rome II criteria

Twelve weeks or more in the last 12 months of abdominal discomfort or pain that has two of the following three features:

1. Relieved by defecation.

2. Associated with a change in frequency of stool.

3. Associated with a change in consistency of stool.

IBS. Vagal nerve dysfunction, ${ }^{23}{ }^{24}$ altered afferent processing, and altered pain threshold to gut distension ${ }^{25}{ }^{26}$ have all been implicated. However, studies are conflicting with problems of reproducibility probably related to patient selection, sedation, and methodological differences. It has been suggested that there is disruption of central processing of gut motility and sensation, with a lot of interest in dynamic magnetic resonance imaging and positron emission tomography scanning looking at abnormal central processing of visceral pain but detailed studies are required to look at this further.

\section{Infectious agents}

Altogether $7 \%-31 \%$ of patients report an episode of antecedent gastroenteritis to their symptoms, ${ }^{27-29}$ but studies are conflicting with factors such stress and anxiety levels being important variables in study outcomes. Serotonin containing enteroendocrine cells have been found in increased concentrations in patients with postinfective IBS, supporting the concept that this subgroup of the syndrome may represent a specific organic disease.

\section{Diet}

Food intolerance is common $(33 \%-66 \%)$ in patients with IBS, ${ }^{30}{ }^{31}$ although studies are conflicting with a large placebo response and true allergies are rare when tested in a double blinded fashion. Many patients are keen to pursue restricted diets and individuals may benefit from exclusion of certain substances. ${ }^{31}$ A true exclusion diet requires an involved and committed dietitian readily contactable by the patient.

Lactose intolerance is common in patients with IBS $(\sim 10 \%)$, depending on the racial mix, but exclusion of lactose from the diet often does not cure the symptoms. Unless a patient drinks in excess of $0.5 \mathrm{pint} / 280 \mathrm{ml}$ of milk per day, it is unlikely that lactose intolerance plays a significant part in their symptomology. ${ }^{32}$

\section{DIAGNOSIS AND INVESTIGATION}

Recent reviews and published guidelines have outlined strategies for diagnosis and management of IBS..$^{1-5} 833$

The diagnosis of IBS is based upon symptom criteria, consideration of patient demographics (that is, age, sex, race) and exclusion of organic disease. A thorough history specifically eliciting alarm symptoms (weight loss, rectal bleeding, nocturnal symptoms), relevant family history, drug and dietary history is important as well as identification of psychosocial aspects. ${ }^{33}$ IBS is a relapsing and remitting condition, and therefore it is important that the investigations are not repeatedly reproduced, but a change in the pattern of symptoms may be important.

A thorough examination and targeted investigations are needed to exclude organic pathology. These include routine full blood count, erythrocyte sedimentation rate, biochemistry, and microbiology with examination of stool for ova, cysts, and parasites. Flexible or rigid sigmoidoscopy should be carried out after the initial consultation, with biopsy of any macroscopic abnormality. Further colonic imaging should be reserved for those over 45 or with a family history of colorectal cancer/polyps. Ultrasonography, computed tomography, and rectal biopsy probably do not increase the diagnostic yield, ${ }^{34-36}$ but if painless diarrhoea is the predominant feature biopsies should be taken to exclude microscopic colitis. Thyroid function tests will reveal approximately $6 \%$ abnormalities and there are few published data regarding the value of calcium levels. Antigliadin and endomysial antibodies have been shown to be useful with the identification of coeliac disease in $5 \%$ of patients with a diagnosis of IBS referred to secondary care. ${ }^{37}$ Further investigations should be targeted according to symptoms. Specialised studies such as anorectal manometry, defecating proctograms, and colonic transit studies should be considered in those with constipation. Lactose hydrogen breath tests, duodenal biopsy and aspiration, and small bowel studies or technetium labelled white cell scans should be reserved for those with diarrhoea or pain or other features indicative of possible inflammatory bowel disease.

\section{MANAGEMENT}

Management of patients with IBS should start with establishing a relationship with the patient with time dedicated to explaining the nature of the condition, treatment options, and impact of anxiety and stress on symptoms. A positive interaction with patients with discussion of precipitating factors, diagnosis, and treatment has been shown to reduce the number of return visits. ${ }^{38}$

Treatment options involve pharmacological (high placebo response $\sim 47 \%$ ) and non-pharmacological approaches, the latter of which particularly in terms of dietary and psychotherapy treatments appear to have the best long term results.

\section{Non-pharmacological therapies}

Simple life style modifications such as dietary manipulation (with exclusion of fibre, caffeine, unrefined carbohydrate, and dairy products), exercise, and defecating patterns may help individual patients. Exclusion diets are used routinely in some practices but require a dedicated dietitian and the evidence for such an approach remains conflicting.

Relaxation therapies and a dedicated psychologist may be of use, with some studies (although few and small) showing a reduction in symptoms and consultations. ${ }^{5}$ Biofeedback in conjunction with relaxation therapies has shown some benefit ${ }^{39} 40$ but studies are felt to be flawed in terms of their methodology, ${ }^{41}$ and the benefit demonstrated may be due to the relationship between therapist and patients. The role of cognitive behavioural therapy and hypnotherapy has not been clearly defined, although small studies suggest some response with symptom improvement. ${ }^{42}{ }^{43}$ Formal psychiatrist referrals should be reserved for those with overt psychotic symptoms or psychiatric conditions.

\section{Pharmacological therapies}

Dietary and drug therapy for IBS can be considered in two categories:

- End organ treatment aimed at relieving abdominal pain (antispasmodic drugs) or disturbed bowel habit (antidiarrhoeal and bulking agents).

- Central treatment (antidepressants, hypnotherapy, psychotherapy) targeted at patients with associated affective disorder.

The British Society of Gastroenterology advises that current drug treatments are of limited value, ${ }^{5}$ but specific symptoms may respond in a small number of patients. If used, drug treatment should be based on the predominant symptoms: abdominal pain, diarrhoea, or constipation (these can change over time). ${ }^{44} 45$ 


\section{Constipation dominant IBS}

In a patient with constipation predominant IBS the traditional advice has been to adopt a high fibre diet. Increasing intake of a range of different dietary "fibres" including those from cereals, fruits, and vegetables have been shown to increase stool weight and accelerate gut transit. ${ }^{5}$ Wheat bran, at doses of $10 \mathrm{~g}$ to $30 \mathrm{~g}$, is the best known and probably the most effective fibre supplement. It increases stool weight and accelerates whole gut transit time. ${ }^{46}$ Symptoms of abdominal pain and bloating, however, increase with bran therapy in most IBS patients. ${ }^{46}{ }^{47}$

Ispaghula husk, a bulking agent, may improve constipation or diarrhoea in patients with IBS. Although there are few studies, it is commonly used in clinical practice to improve stool frequency as it has less of the adverse effects associated with wheat bran. ${ }^{4}$ A systematic review of 70 randomised controlled trials of various drug treatments for IBS concluded that calcium polycarbophil and ispagula husk were associated with an improvement in constipation but no improvement in other symptoms. ${ }^{48}$ An osmotic laxative or stool softener may be added in patients who fail to respond to fibre, but stimulant laxatives should be avoided. The efficacy of bulking agents has not been clearly established and bran should only be used when constipation is a major feature, starting at low doses and increasing gradually.

Antimuscarinic agents, such as dicyclomine hydrochloride and hyoscine butylbromide, are believed to directly relax intestinal smooth muscle. Other intestinal relaxants that are commonly used in the treatment of IBS include alverine citrate, mebeverine hydrochloride, and peppermint oil. In a recent well designed study, alverine citrate was no better than placebo in relieving the symptoms of IBS..$^{49}$ Dicyclomine has been reported to improve abdominal pain and constipation, but most patients (69\% $v 16 \%$ placebo) experienced anticholinergic side effects with this drug. A therapeutic trial of an antimuscarinic drug, given before meals, may be beneficial in patients who have episodes of abdominal pain after eating, but randomised clinical trials demonstrate little, if any, advantage over placebo, and significant risk of mild side effects. ${ }^{48}$

IBS patients with constipation and bloating have been considered as possible candidates for a prokinetic agent. Although prokinetic drugs, such as metoclopramide or domperidone, do not show activity on the large bowel, cisapride has been suggested to be of benefit in constipation predominant IBS. Cisapride (now withdrawn in the UK) can accelerate gastric emptying but was not shown to improve abdominal pain, constipation, or abdominal bloating. ${ }^{45}$ Selective serotonin-4 $\left(5-\mathrm{HT}_{4}\right)$ receptor agonists have prokinetic activity and are currently under evaluation in functional bowel disorders, particularly constipation predominant IBS..$^{45}$

\section{Diarrhoea dominant IBS}

Diarrhoea dominant IBS is associated with acceleration of small bowel and proximal colonic transit and responds to opioids. ${ }^{50} \mathrm{~A}$ drawback of opioid use is the tendency to induce constipation. As a result, the dose should be titrated for the individual patient.

Loperamide is an opioid analogue which slows small and large intestinal transit and decreases stool frequency and urgency in patients with IBS at doses of 4-12 mg each day. It has poor blood-brain barrier penetration and is therefore preferable to opioids with a central action, such as diphenoxylate or codeine, as there is less risk of dependence. ${ }^{4}$ Codeine, at doses of $15-30 \mathrm{mg} \mathrm{l}-3$ times daily, is effective in functional diarrhoea but is more likely to cause sedation and drug dependency. ${ }^{5}$

A few patients with diarrhoea predominant IBS have bile salt malabsorption and may respond to cholestyramine. ${ }^{5}$ The tolerability of cholestyramine is poor with side effects such as constipation and diarrhoea, as well as nausea, vomiting, and gastrointestinal discomfort. ${ }^{51}$
Motility and intestinal transit are also inhibited to some degree through serotonin-3 (5- $\left.\mathrm{HT}_{3}\right)$ and muscarinic $\mathrm{M}_{3}$ receptors. Drugs which reduce contractile activity or visceral perception offer promise in diarrhoea predominant IBS. 5- $\mathrm{HT}_{3}$ receptor antagonists do not alter gastric emptying or small intestine transit but do increase colonic transit time. ${ }^{52}$ This explains the tendency of these drugs to cause constipation in healthy volunteers resulting in decreased bowel frequency and altered stool consistency in diarrhoea predominant IBS. In a double blind, placebo controlled study on 50 patients with IBS, ondansetron reduced bowel frequency and improved stool consistency in the diarrhoea predominant group. ${ }^{52}$

Alosetron is a $5-\mathrm{HT}_{3}$ receptor antagonist. It was launched for diarrhoea predominant IBS in females in the United States but was voluntarily withdrawn by the manufacturers in November 2000. There were concerns about severe constipation and ischaemic colitis (in some cases fatal) which had occurred in patients taking alosetron for IBS.

\section{Antidepressants}

There is a large psychological component to IBS, including symptoms of depression, anxiety, phobia, and somatisation. ${ }^{44}$ Antidepressants have many actions that are effective in the treatment of IBS. As well as treating underlying depression, they modify gut motility, alter visceral nerve responses, and have analgesic properties that may benefit certain patients. ${ }^{5}$ Tricyclic antidepressants tend to slow gut transit while the specific serotonin reuptake inhibitors (SSRI) tend to produce more rapid transit, particularly in the small intestine. ${ }^{45}$ Therefore, SSRIs may be more appropriate in constipation predominant IBS but this effect is still under evaluation. Tricyclic antidepressants may need to be used cautiously in certain patients as they can cause or aggravate constipation. The effectiveness of SSRIs in the management of IBS is yet to be established.

\section{New drugs}

Following on from the interest in the role of serotonin in the modulation of gut motility and visceral sensitivity in IBS, a new generation of prokinetics has been developed including several partial agonists at the $5-\mathrm{HT}_{4}$ receptor, such as tegaserod and prucalopride. These seem to be devoid of the QT prolonging effects observed in some clinical circumstances with cisapride and may be more active at the colonic level. ${ }^{52}$

Tegaserod (Zelmac) is a relatively specific $5-\mathrm{HT}_{4}$ partial agonist but may also facilitate enteric cholinergic transmission. In a short term study tegaserod accelerates orocaecal transit without altering gastric emptying in female patients with constipation predominant IBS. No serious adverse events were reported. ${ }^{53}$ In another study, however, tegasarod markedly accelerated gastric emptying and shortened intestinal and colonic transit times in healthy male subjects. ${ }^{54}$ At present tegaserod is only licensed in United States for women with constipation predominant IBS. Additional studies are required to explore the role of this drug, which may potentially offer advantages over currently available prokinetic drugs for the treatment of constipation predominant IBS.

Another $5-\mathrm{HT}_{4}$ receptor agonist, prucalopride, may be useful in patients with constipation predominant IBS. A double blind study evaluated the effects of prucalopride in constipation, and concluded that it accelerates transit through the stomach, small bowel, and colon in patients with constipation unassociated with a rectal evacuation disorder.5 ${ }^{55}$ In a multicentre, randomised, double blind, 12 week study in 251 patients with chronic constipation, prucalopride significantly increased stool frequency and consistency. ${ }^{56}$

The primary outcome measure in the treatment of IBS is to control the patient's symptoms (pain, diarrhoea, constipation). Symptoms may fluctuate over time and treatment is often restricted to times when patients experience a relapse. Robust clinical trials are required before these new pharmacological agents can be recommended for IBS treatment, and 


\section{Box 2: Useful addresses}

- IBS Bulletin, Free Post TK 1409, Hampton Hill, Middlesex TW12 IBR, UK (freephone 0800783 7327).

- Penny Nunn, IBS Network, Northern General Hospital, Sheffield S5 7AU, UK (tel 01142611531 ).

\section{Box 3: Useful websites}

- Gastroenterology Association Public Section: www.gastro.org/ibs.html-American

- National Institute of Health listings of organisations: www.gov/medlineplus/organisations.html

\section{Box 4: Top five references}

- Jones J, Boorman J, Cann P, et al. British Society of Gastroenterology guidelines for the management of the irritable bowel syndrome. Gut 2000;47(suppl 2):ii 1-19.

- Drossman DA, Corazziari E, Talley NJ, et al. Rome II: a multinational consensus document on functional gastrointestinal disorders. Gut 1999;45(suppl 11):1-81.

- Camilleri M. Management of the irritable bowel syndrome. Gastroenterology 2001;120:652-68.

- Talley NJ, Spiller R. Irritable bowel syndrome: a little understood organic bowel disease? Lancet 2002;360:555-64

- Olden KW. Diagnosis of irritable bowel syndrome. Gastroenterology 2002;122:1701-4.

\section{Questions (answers at end of references)}

1. With what psychosocial features is IBS associated?

2. What investigations are appropriate in suspected IBS?

3. Should patients be advised to increase dietary fibre?

confidence about long term safety will require vigilant post marketing surveillance.

\section{SUMMARY}

The management of IBS involves a positive approach with establishment of a relationship with the patient from the initial consultation. Diagnosis is predominantly clinical, with exclusion of pathology using the minimum of investigations, targeted according to the age and alarm symptoms. Management requires a combination of reassurance, explanation of the chronic relapsing remitting nature of the condition and pharmacological and non-pharmacological therapies; it should be explained that response to therapy is variable. A multidisciplinary approach to resistant cases can be of value.

\section{Authors' affiliations}

M C Gunn, A A Cavin, J C Mansfield, Royal Victoria Infirmary, Newcastle upon Tyne

\section{REFERENCES}

1 Talley NJ, Spiller R. Irritable bowel syndrome: a little understood organic bowel disease? Lancet 2002;360:555-64.

2 Thompson WG. Review article: the treatment of irritable bowel syndrome. Aliment Pharmacol Ther 2002;16:1395-406.

3 Camilleri M, Heading RC, Thompson WG. Consensus report: clinical perspectives, mechanisms, diagnosis and management of irritable bowel syndrome. Aliment Pharmacol Ther 2002;16:1407-30.

4 Camilleri M. Management of the irritable bowel syndrome. Gastroenterology 2001;120:652-68.
5 Jones J, Boorman J, Cann P, et al. British Society of Gastroenterology guidelines for the management of the irritable bowel syndrome. Gut 2000;47(suppl 2):ii 1-19.

6 Drossman DA, Corazziari E, Talley NJ, et al. Rome II: a multinational consensus document on functional gastrointestinal disorders. Gut 1999;45(suppl 11): 1-81

7 Manning AP, Thompson WG, Heaton KW, et al. Towards positive diagnosis of the irritable bowel. BM 1978;ii:653-4.

8 Drossman DA, Whitehead WE, Camilleri M. Irritable bowel syndrome: a technical review for practice guideline development. Gastroenterology 1997; 1 12:2120-37.

9 Talley NJ, Zinsmeister AR, Melton LJ. Irritable bowel syndrome in a community: symptom subgroups, risk factors and health care utilisation. Am J Epidemiol 1995; 142:76-83.

10 Talley NJ, O'Keefe EA, Zinsmeister AR, et al. Prevalence of gastrointestinal symptoms in the elderly: a population based study. Gastroenterology 1992;102:895-901.

11 Jones R, Lydreard S. Irritable bowel syndrome in the general population. BM 1992;304:87-90

12 Heaton KW, O'Donnell $\amalg$, Braddon FE, et al. Symptoms of irritable bowel syndrome in a British urban community: consulters and nonconsulters. Gastroenterology 1992;102:1962-7.

13 Thompson WG, Creed F, Drossman DA, et al. Functional bowel disease and functional abdominal pain. Gastroenterology International 1992:5:75-91.

14 Lonstreth GF, Preskill DB, Youkeles L. Irritable bowel syndrome in women having diagnostic laparoscopy or hysterectomy. Relation to gynaecological features and outcome. Dig Dis Sci 1990;35:1285-90.

15 Talley NJ, Gabriel SE, Harmsen WS, et al. Medical costs in community subjects with irritable bowel syndrome. Gastroenterology subjects with irritable

16 Camilleri $M$, Williams DE. Economic burden of irritable bowel syndrome reappraised with strategies to control expenditure. Pharmacoeconomics 2000;4:331-8.

17 Corney RH, Stanton R. Physical symptom severity, psychological and social dysfunction in a series of outpatients with irritable bowel syndrome. J Psychosom Res 1990:34:483-91.

18 Drossman DA, Li Z, Andruzzi E, et al. US householder survey of functional gastrointestinal disorders. Dig Dis Sci 1993;38:1569-80.

19 Delvaux M, Denis P, Allemand H. Sexual abuse is more frequently reported by IBS patients than by patients with organic digestive disease or controls. Results of a multicentre inquiry. Eur J Gastroenterol Hepatol 1997:9:345-52.

20 Drossman DA, Leserman J, Nachman G, et al. Sexual and physical abuse in women with functional or organic gastrointestinal disorders. Ann Intern Med 1990;1 13:828-33.

21 Whitehead WE, Winget C, Fedoravicius AS, et al. Learned illness behavior in patients with irritable bowel syndrome and peptic ulcer. Dig Dis Sci 1982;27:202-8.

22 Van Der Horst HE, Van Dulmen AM. Do patients with irritable bowel syndrome in primary care really differ from outpatients with irritable bowel. Gut 1997;42:669-74.

23 Aggarwal A, Cutts TF, Abell TL, et al. Predominant symptoms in irritable bowel correlate with specific autonomic nervous system abnormalities. Gastroenterology 1994:106:945-50.

24 Bharucha AE, Camilleri M, Low PA, et al. Autonomic dysfunction in gastrointestinal motility disorders. Gut 1993;34:397-401.

25 Ritchie J. Pain from distension of the pelvic colon by inflating a balloon in the irritable colon syndrome. Gut 1973;14:125-32.

26 Whitehead WE, Holtkotter B, Enck $\mathrm{P}$, et al. Tolerance for rectosigmoid distention in irritable bowel syndrome. Gastroenterology 1990;98(5 pt 1): $1187-92$.

27 Gwee KA, Graham JC, Mckendrick MW, et al. Psychometric scores and persistence of irritable bowel after infectious diarrhoea. Lancet persistence of irritable

28 Gwee KA, Leong YL, Graham C, et al. The role of psychological and biological factors in postinfective gut dysfunction. Gut 1999;44:400-6.

29 Neal KR, Hedben J, Spiller R. Prevalence of gastrointestinal symptoms six months after bacterial gastroenteritis and risk factors for development of the irritable bowel syndrome: postal survey of patients. BM 1997:314:779-82.

30 Jones VA, Mclaughlan P, Shorthouse M, et al. Food intolerance: a major factor in the pathogenesis of irritable bowel syndrome. Lancet 1982;ii: $1115-7$.

31 Nanda $R$, James $R$, Smith $H$, et al. Food intolerance and the irritable bowel syndrome Gut 1989:30:1098-104.

32 Suarez FL, Savaiano DA, Levitt MD. A comparison of symptoms after the consumption of milk or hydrolysed milk by people with self reported severe lactose intolerance. N Engl J Med 1995;333:1-4

33 Olden KW. Diagnosis of irritable bowel syndrome. Gastroenterology 2002;122:1701-4.

34 Francis $\mathrm{CY}$, Duffy JN, Whorwell PJ, et al. Does routine abdominal ultrasound enhance diagnostic accuracy in irritable bowel syndrome? Am J Gastroenterol 1996:91:1348-50.

35 Macintosh DG, Thompson WG, Patel DG, et al. Is rectal biopsy necessary in irritable bowel syndrome? Am J Gastroenterol 1992;87:1407-9

36 Thompson WG, Heaton KW, Smyth GT, et al. Irritable bowel syndrome: the view from general practice. Eur J Gastroenterol Hepatol 1997:9:689-92.

37 Sanders DS, Carter M, Hurlstone DP, et al. Association of adult coeliac disease with irritable bowel syndrome: a case-control study in patients 
fulfilling Rome II criteria referred to secondary care. Lancet 2001;358:1504-8.

38 Owens DM, Nelson DK, Talley NJ. The irritable bowel syndrome: long term prognosis and the physician-patient interaction. Ann Intern Med 1995; 122:107-12

39 Lynch PM, Zamble E. A controlled behavioural treatment study of irritable bowel syndrome. Behav Ther 1989;20:509-23.

40 Neff DF, Blanchard EB. A multi-component treatment for irritable bowel syndrome. Behav Ther 1987;18:70-83

41 Talley NJ, Owen BK, Boyce P, et al. Psychological treatments for irritable bowel syndrome: a critique of controlled treatment trials. Am J Gastroenterol 1996:91:277-83.

42 Whorell PJ. Hypnotherapy in the irritable bowel syndrome. Stress Medicine 1987;3:5-7.

43 Payne A, Blanchard EB. Controlled comparison of cognitive therapy and self-help support groups in the treatment of irritable bowel syndrome. J Consult Clin Psychol 1995;63:779-86.

44 Farthing MJG. Fortnightly review: irritable bowel, irritable body, or irritable brain? BM 1995:310:171-5.

45 Farthing MJG. New drugs in the management of the irritable bowel syndrome. Drugs 1998;56:11-21.

46 Cann PA, Read NW, Holdsworth CD. What is the benefit of coarse wheat bran in patients with irritable bowel syndrome? Gut 1984;25: 168-73.

47 Francis CY, Whorwell PJ. Bran and irritable bowel syndrome: time for reappraisal. Lancet 1994;344:39-40.

48 Jaiwala J, Imperiale TF, Kroenke K. Pharmacologic: treatment of the irritable bowel syndrome: a systematic review of randomised, controlled trials. Ann Intern Med 2000;133:136-45.

49 Mitchell SA, Mee AS, Smith GD, et al. Alverine citrate fails to relieve the symptoms of irritable bowel syndrome: results of a double-blind, randomized, placebo-controlled trial. Aliment Pharmacol Ther 2002;16:1 187-95.
50 Klein KB. Controlled treatment trials in the irritable bowel syndrome: a critique Gastroenterology 1988:95:232-41.

51 Williams AK, Merrick MV, Eastwood MA. Idiopathic bile acid malabsorption. A review of clinical presentation, diagnosis and response to treatment. Gut 1991;32:1004-6.

52 De Ponti F, Tonini M. Irritable bowel syndrome. New agents targeting serotonin receptor subtypes. Drugs 2001;61:317-32.

53 Prather CM, Camilleri M, Zinsmeister AR, et al. Tegaserod accelerates orocecal transit in patients with constipation-predominant irritable bowel syndrome. Gastroenterology 2000;1 18:463-8.

54 Degen L, Matzinger D, Merz M, et al. Tegaserod, a $5-\mathrm{HT}_{4}$ receptor partial agonist, accelerates gastric emptying and gastrointestinal transit in healthy male subjects. Aliment Pharmacol Ther 2001;15:1745-51.

55 Bouras EP, Camilleri M, Burton DD, et al. Prucalopride accelerates gastrointestinal and colonic transit in patients with constipation without a rectal evacuation disorder. Gastronterology 2001;120:354-60.

56 Otten M, Schneider H, Wurzer H, et al. A double blind, placebo controlled evaluation of safety and efficacy of 12 week, twice daily treatment with prucalopride in patients with chronic constipation. Gastroenterology 1999;116:1055.

\section{ANSWERS}

1. Physical and sexual abuse is twice as common in IBS than in organic gastrointestinal disease.

2. In the absence of alarm symptoms investigation should be limited to those required to support reassurance.

3. Increasing dietary fibre may improve constipation, but other symptoms of IBS are likely to be made worse by this change.

IMAGES IN MEDICINE.

Plantar fibromatosis

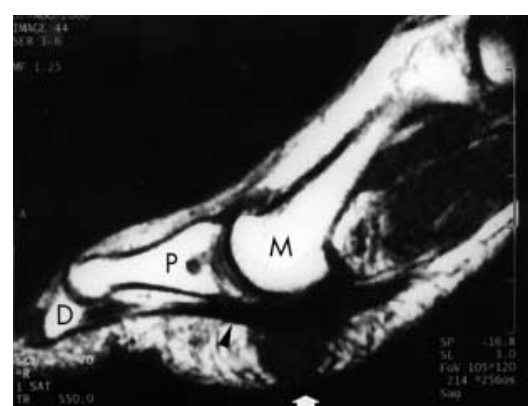

Figure $1 M R I, T 1$-weighted image; $D$ distal phalanx; $M$, metatarsal bone; $P$, proximal phalanx.

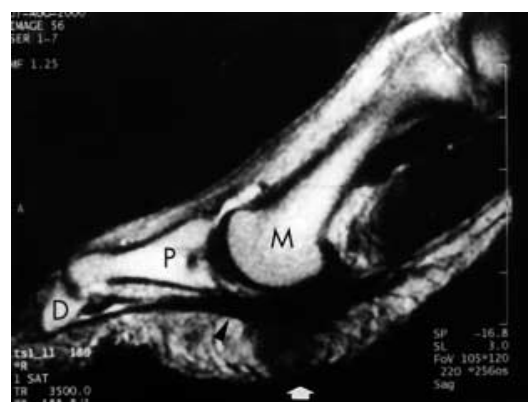

Figure 2 MRI, T2-weighted image; $D$, distal phalanx; $M$, metatarsal bone; $P$, proximal phalanx.
56 year old woman presented with a hard subcutaneous mass in the plantar aspect of the right foot. This isolated mass demonstrated slow growth over four months, but there was no local pain or fever. On magnetic resonance imaging (MRI), the tumour was demonstrated as a subcutaneous mass with low signal intensity both on Tl and T2-weighted images (figs 1 and 2, arrows), indicating fibrous matrix. The mass showed marked enhancement on enhanced Tl-weighted image (fig 3, arrow), contained a cystic change (not shown), and broadly adjoined the flexor hallucis longus tendon (arrowheads). At surgery, a white hard mass with a cavity was found to arise from the plantar aponeurosis. Histological examination revealed a benign reactive proliferation of dense collagenous matrix with markedly enlarged vessels. There has not been any recurrence for 18 months after surgery.

Plantar fibromatosis (Ledderhose disease) is a benign but infiltrative neoplasm, and is a slow growing nodular thickening that occurs most often within the central band of the plantar aponeurosis. MRI is especially useful in planning surgical treatment by showing the exact location and extent of the lesion.

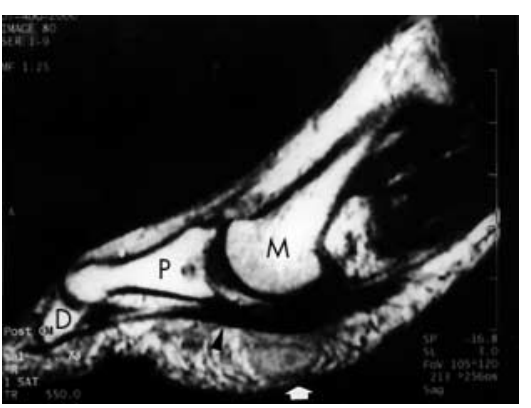

S Yoshida, M Shidoh Department of Radiology, Muroran City General Hospital Yamate-chou 3-8-1, Muroran 051-8512, Japan mumuh003@swan-bay.ne.jp
Figure $3 \mathrm{MRI}$, enhanced Tl-weighted image; $D$, distal phalanx; $M$, metatarsal bone; $P$, proximal phalanx. 